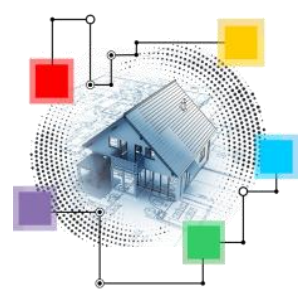

\author{
XIII SIMPÓSIO NACIONAL DE SISTEMAS PREDIAIS \\ DESEMPENHO E INOVAÇÃO \\ DE SISTEMAS PREDIAIS HIDRÁULICOS \\ SÃO PAULO - 04 DE OUTURO DE 2019
}

\title{
ANÁLISE HIERÁRQUICA PARA APERFEIÇOAMENTO DE UMA FERRAMENTA DE AVALIAÇÃO DE PROJETOS HIDRÁULICOS E SANITÁRIOS PREDIAIS
}

\section{HIERARCHICAL ANALYSIS FOR IMPROVING A PLUMBING DESIGN EVALUATION TOOL}

\author{
PAIXÃO, Thyago Cesar Rodrigues ${ }^{1}$; REIS, Ricardo Prado Abreu² \\ ${ }^{1}$ Escola de Engenharia Civil e Ambiental da Universidade Federal de Goiás, thiagoovfreitas@ gmail.com \\ ${ }^{2}$ Escola de Engenharia Civil e Ambiental da Universidade Federal de Goiás, ricardo_reis@ufg.br
}

\begin{abstract}
RESUMO
Nas edificações, a incidência das patologias nos Sistemas Prediais Hidráulicos e Sanitários (SPHS), ainda é grande. Paixão, Silva e Reis (2016) propuseram uma ferramenta de avaliação qualitativa dos projetos desses sistemas, abrangendo os sistemas de água fria, água quente, esgoto sanitário e águas pluviais, e que se propõe a auxiliar na identificação das não conformidades nesses projetos. No entanto, a ferramenta proposta por Paixão, Silva e Reis (2016) possui a limitação de não considerar a gravidade das não conformidades e nem a sua repetitividade no projeto. Diante disso, o objetivo desse trabalho foi aprimorar a ferramenta, de modo que esses dois pontos pudessem ser considerados, por meio da hierarquização das não conformidades, atribuindo pesos a elas, e da reestruturação da ferramenta proposta. Além disso, itens de não conformidade referentes à sustentabilidade ambiental aplicada a projetos foram acrescentados à ferramenta, refletindo em um novo grupo de não conformidades: sustentabilidade. Assim, obteve-se como resultado, através da aplicação do método de análise hierárquica (AHP) a profissionais projetistas e executores desses sistemas, pesos relativos atribuídos por classe de profissional, além de uma ferramenta aprimorada e ajustada quanto à sua estrutura, fazendo com que passe a auxiliar na priorização das ações a serem tomadas para corrigir as não conformidades identificadas.
\end{abstract}

Palavras-chave: Construção Civil. Sistemas Prediais Hidráulicos e Sanitários. Patologia das Construções. Qualidade de Projeto. Método de Análise Hierárquica.

\begin{abstract}
The pathologies incidence in Buildings Plumbing Systems is still high. Paixão, Silva e Reis (2016) proposed a qualitative assessment tool for these systems project design, covering: cold water, hot water, sewage and stormwater drainage systems, which aims to assist in nonconformities identification in these projects. However, the tool proposed by Paixão, Silva e Reis (2016) has the limitation of not considering the severity of nonconformities or their repetitiveness in the project. Given this, the aim of this research was to improve this tool, considering the improvement of these two points, through the hierarchy and weighting of nonconformities, in addition to the restructuring of the proposed tool. In addition, nonconformity items related to environmental sustainability applied to projects were added to the tool, reflecting in a new group of nonconformities: sustainability. Through the application of the Hierarchical Analysis Method to plumbing designers and buildings executors, it was possible to define relative weights attributed by professional class. This allowed an adjustment in the structure of the plumbing design evaluation tool allowing its improvement, enabling it to assist in priority actions to correct identified nonconformities.
\end{abstract}

Keywords: Plumbing Systems, Construction Pathology, Project Desingn Quality, Hierarchical Analysis Method. 


\section{INTRODUÇÃO}

Nos últimos anos, no Brasil, aumentou-se no setor da construção civil a preocupação em relação à qualidade nos processos de concepção e execução de obras. Aliando as inovações tecnológicas na indústria da construção à crescente exigência de qualidade dos clientes, amparados legalmente pelo Código de Defesa do Consumidor, e à necessidade de redução de desperdícios, as empresas construtoras vêm tentando se manterem competitivas no mercado. Assim, o estudo das falhas construtivas na engenharia começou a ser tratado de forma mais sistematizada, visando possibilitar uma retroalimentação dos processos com a finalidade de melhorar a qualidade no ambiente construtivo. Apesar disso, nas edificações, a frequência de incidência e as causas das patologias nos Sistemas considerados "complementares", dentre eles os Sistemas Prediais Hidráulicos e Sanitários (SPHS), ainda é grande e têm sido pouco pesquisadas (PAIXÃO; SILVA e REIS, 2016).

As principais ocorrências patológicas em edificações estão relacionadas aos sistemas prediais hidráulicos e sanitários. Muitas dessas patologias acontecem repetitivamente nos edifícios, revelando falhas sistemáticas. Daí a importância do estudo dessas patologias, visando possibilitar uma atuação preventiva e melhoria da qualidade, especialmente na fase de projeto. Ressalta-se ainda que intervenções nessa fase normalmente são de baixo custo se comparadas às fases posteriores (CARVALHO JUNIOR, 2013; GNIPPER, 2010; PAIXÃO; SILVA e REIS, 2016; SILVA, 2008).

Paixão, Silva e Reis (2016) propuseram uma ferramenta de avaliação qualitativa de projetos hidráulicos e sanitários de edificações, em forma de lista de verificações (check-list), no qual as principais patologias que incidem sobre esses sistemas foram relacionadas a não conformidades de boas práticas de projeto ou normativas. Tal ferramenta abrange os sistemas de água fria, água quente, esgoto sanitário e águas pluviais, e se propõe a auxiliar na identificação das não conformidades recorrentes nos projetos desses sistemas.

A ferramenta proposta pode ser aplicada em qualquer fase da vida útil da edificação, tanto para prevenir manifestações patológicas futuras, quanto para auxiliar na compreensão de manifestações patológicas já instaladas (PAIXÃO; SILVA e REIS, 2016).

No entanto, a ferramenta proposta por Paixão, Silva e Reis (2016) não leva em consideração a gravidade das não conformidades, nem mesmo a quantidade observada (repetitividade). Desta forma, o objetivo deste trabalho é incorporar a gravidade e a repetitividade das não conformidades dos projetos dos Sistemas Prediais Hidráulicos e Sanitários na ferramenta proposta por Paixão, Silva e Reis (2016), por meio da hierarquização destas não conformidades pela aplicação do Método de Análise Hierárquica (AHP).

\section{REVISÃO BIBLIOGRÁFICA}

\subsection{Patologias nos sistemas prediais hidráulicos e sanitários}

Os processos patológicos nos Sistemas Prediais Hidráulicos e Sanitários podem ter origem em qualquer umas das fases da vida útil da edificação. Carvalho Junior (2013) cita que as principais causas de patologias em sistemas prediais hidráulicos e sanitários de origem endógena, ou seja, originadas por fatores inerentes à própria edificação, são: falhas de projeto $(40 \%)$, falhas de execução (28\%), qualidade dos materiais (18\%), uso das instalações (10\%), e diversos (4\%). As patologias decorrentes do projeto, conforme exposto, são as que tem maior representatividade nos SPHS. 


\subsection{Sustentabilidade ambiental em projetos de sistemas prediais hidráulicos e sanitários}

A sustentabilidade ambiental, principalmente em relação à água, é um assunto mundialmente discutido. Uma das soluções para os conflitos relacionados ao uso da água, é a gestão dos recursos hídricos. Dentre as ações para a gestão dos recursos hídricos, segundo Sautchuck et al. (2005), estão a diminuição da geração de efluentes, gestão da demanda, redução de perdas e práticas conservacionistas. Além disso, o reuso das águas servidas do sistema predial de esgoto sanitário é uma forma de economizar água potável, conservando assim os recursos hídricos disponíveis.

Os projetos hidráulicos e sanitários prediais sustentáveis não estão ligados apenas à gestão de recursos hídricos. Os sistemas e elementos prediais que contribuem com a drenagem urbana, por meio de aproveitamento das águas pluviais ou de elementos de drenagem na fonte, e a preocupação com a eficiência energética nas instalações prediais, principalmente em relação ao sistema predial de água quente, também se incluem nessa esfera.

Desta forma, os projetistas de sistemas prediais hidráulicos e sanitários estão cada vez mais buscando a inclusão de itens de sustentabilidade ambiental em seus projetos, quando apresentam viabilidade técnica e econômica.

\subsection{Método de análise hierárquica}

O método de análise hierárquica AHP (em inglês - Analytic Hierarchy Process), tem como objetivo principal, estimar a prioridade de cada alternativa dentro de um conjunto de alternativas (PASSOS, 2010).

O AHP transforma uma difícil decisão em algumas decisões mais simples. Tendo-se o objetivo geral, os critérios a serem considerados e as alternativas, os tomadores da decisão fazem as comparações entre os elementos, determinado a prioridade de um elemento sobre o outro. Os resultados obtidos por essas comparações, geram as matrizes de comparação ou matrizes de julgamento, como mostra a matriz da Figura 1 (WOLFF, 2008).

\section{FIGURA 1 - Matriz-exemplo de comparação}

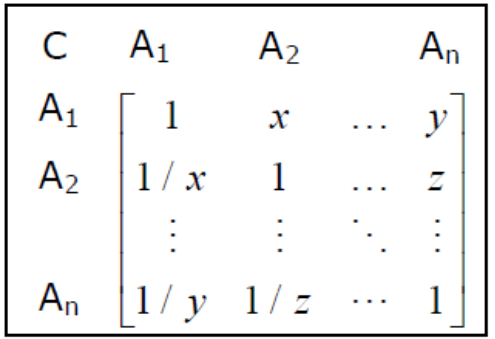

Fonte: Wolff (2008).

Para preencher essa matriz geralmente é utilizada uma escala conhecida como Escala Fundamental de Saaty, com valores de 1 a 9, em que 1 indica que a prioridade entre os dois itens avaliados é igual, e 9 indica que a prioridade de um item é extremamente maior que a prioridade do outro.

Para uma matriz de comparação ser absolutamente consistente, esta matriz deve satisfazer as Equações 1 e 2 (WOLFF, 2008).

$$
a_{j i}=1 / a_{i j}
$$


$a_{i j} * a_{j k}=a_{i k}$

Após a realização de todas as comparações paritárias e o preenchimento das matrizes de comparação, deve-se trabalhar essas matrizes para se obter o resultado final. No AHP, ao final da aplicação do método, cada alternativa receberá uma pontuação, um peso relativo, obtendose assim a prioridade de cada uma.

Mesmo não existindo limitação para a quantidade de alternativas, quando há grande número de comparações exigidas é normal que haja desatenção por parte dos tomadores da decisão no momento das comparações, acarretando julgamentos equivocados (GOMES, 2009).

Leal (2008, apud WOLF, 2008) propõe uma simplificação do modelo AHP, admitindo consistência absoluta, aproximando-se numericamente das prioridades alcançadas pelos métodos tradicionais. A maior vantagem dessa simplificação é a grande redução do número de comparações, de $n *(n-1) / 2$ para n-1.

\section{MÉTODO}

Para se aprimorar a ferramenta de análise de projetos dos Sistemas Prediais Hidráulicos e Sanitários proposta por Paixão, Silva e Reis (2016) fez-se uso do Método de Análise Hierárquica (AHP). Para tal, foi seguida a sequência do AHP apresentada na Figura 2, adaptada da proposta de Vieira (2006, apud GOMES, 2009).

FIGURA 2 - Sequência de aplicação do AHP neste trabalho.

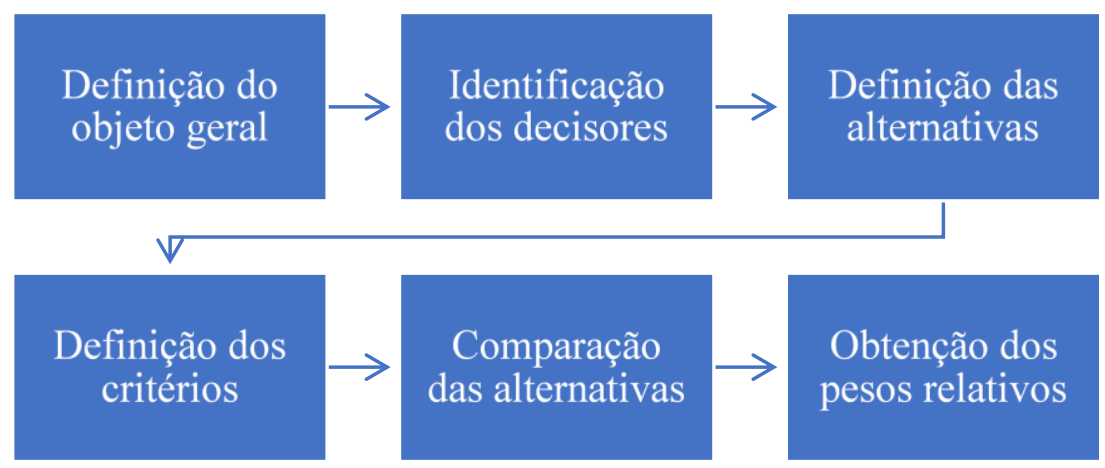

Fonte: Adaptado de Vieira (2006, apud Gomes, 2009).

O primeiro passo foi a definição do objeto geral, ou seja, a decisão que se pretende tomar. No caso foi hierarquizar (determinando pesos) as não conformidades de projeto dos sistemas prediais hidráulicos e sanitários abordados na pesquisa. A cada sistema foi aplicado o AHP, individualmente.

A identificação dos decisores se deu pela busca de profissionais projetistas e executores de sistemas prediais hidráulicos e sanitários que possuíssem experiência e conhecimento específico.

A definição das alternativas se deu pela revisão, complementação e atualização dos itens de não conformidades apresentados por Paixão, Silva e Reis (2016).

Há um único critério de hierarquização das alternativas: a relevância e potencialidade patológica da não conformidade, ou seja, a gravidade técnica e econômica da manifestação patológica que pode ser gerada pela não conformidade.

Para a comparação das alternativas, foi aplicada a simplificação do modelo AHP proposta por Leal (2008, apud WOLF, 2008), devido ao elevado número de comparações que seriam 
exigidas pelo método tradicional. Foi usada ainda uma versão adaptada da Escala Fundamental de Saaty, com valores variando de 1 até 7.

Os tomadores da decisão (projetistas e executores) fizeram a comparação das alternativas. Assim, foi montada a matriz de comparações paritárias. De posse dessas matrizes foi obtido o peso relativo de cada uma das alternativas (não conformidades).

Os check-lists elaborados por Paixão, Silva e Reis (2016) foram revisados e atualizados, sendo criado um novo subgrupo, "sustentabilidade", referente a elementos de sustentabilidade ambiental abordados nos SPHS, e ainda uma nova coluna na estrutura dos check-lists, para incluir o levantamento da quantidade de vezes que o item se mostrou presente no projeto analisado. Esse último dado é utilizado para adequar os pesos dos itens no momento da aplicação da ferramenta. Deste modo, a consideração da repetitividade ajusta os pesos das não conformidades para o projeto analisado.

\section{RESULTADOS}

Os resultados dos julgamentos dos profissionais envolvidos na pesquisa se mostraram bastante dispersos, explicitando a existência de diferentes pontos de vista entre eles. A despeito do indicado por Saaty e Vargas (2003, apud WOLFF, 2008), preferiu-se manter a teoria de Rabbani e Rabbani (1996, apud WOLFF, 2008) que concluem que a média geométrica é a única média que funciona adequadamente no método AHP para representar o julgamento médio.

A seguir são apresentadas as médias geométricas dos resultados dos julgamentos para cada sistema (Figuras 3 a 6). São apresentadas a média dos seis projetistas, a média dos três executores e a média geral dos nove profissionais.

FIGURA 3 - Hierarquização para o Sistema Predial de Água Fria.

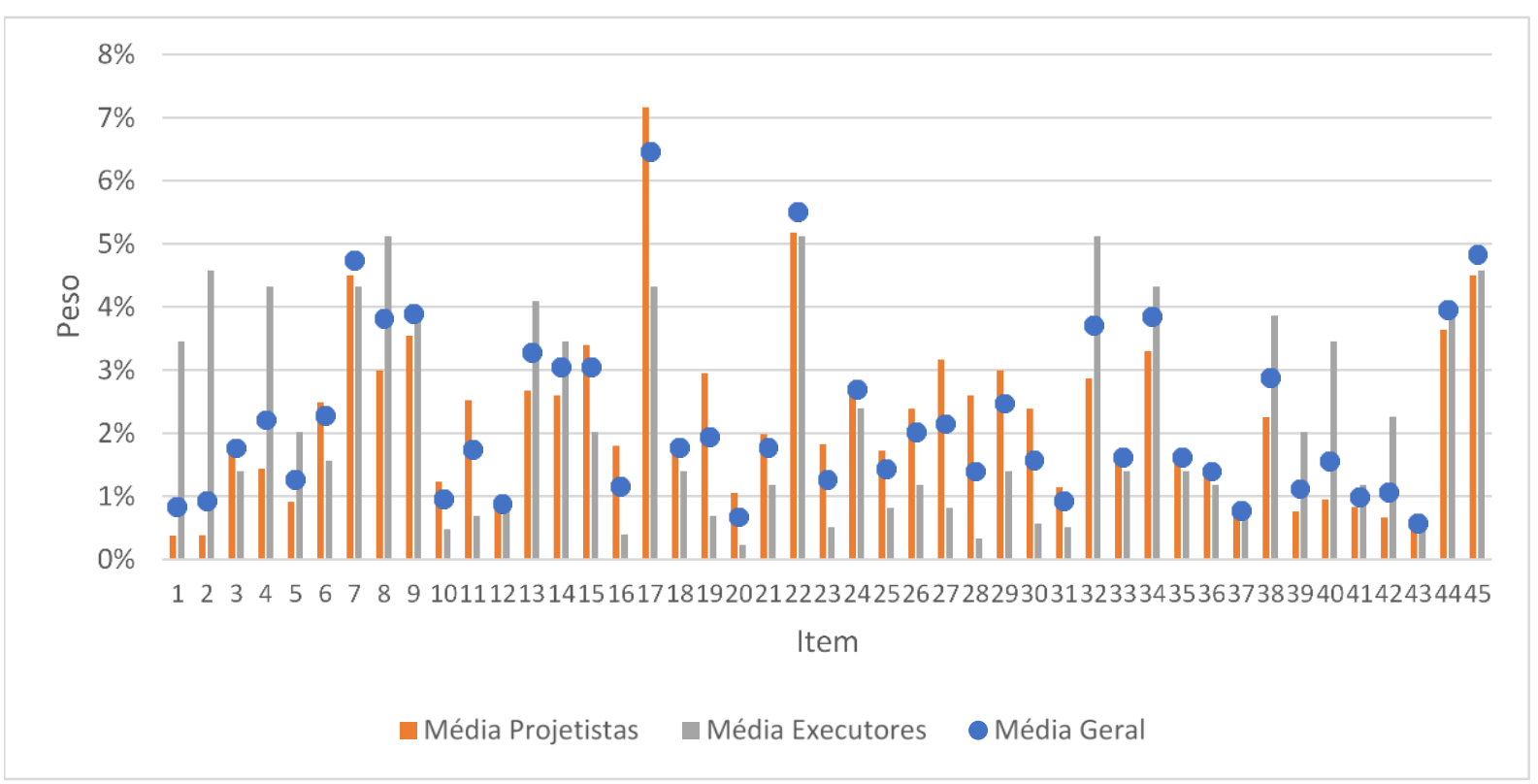

Fonte: Os autores. 
FIGURA 4 - Hierarquização para o Sistema Predial de Água Quente.

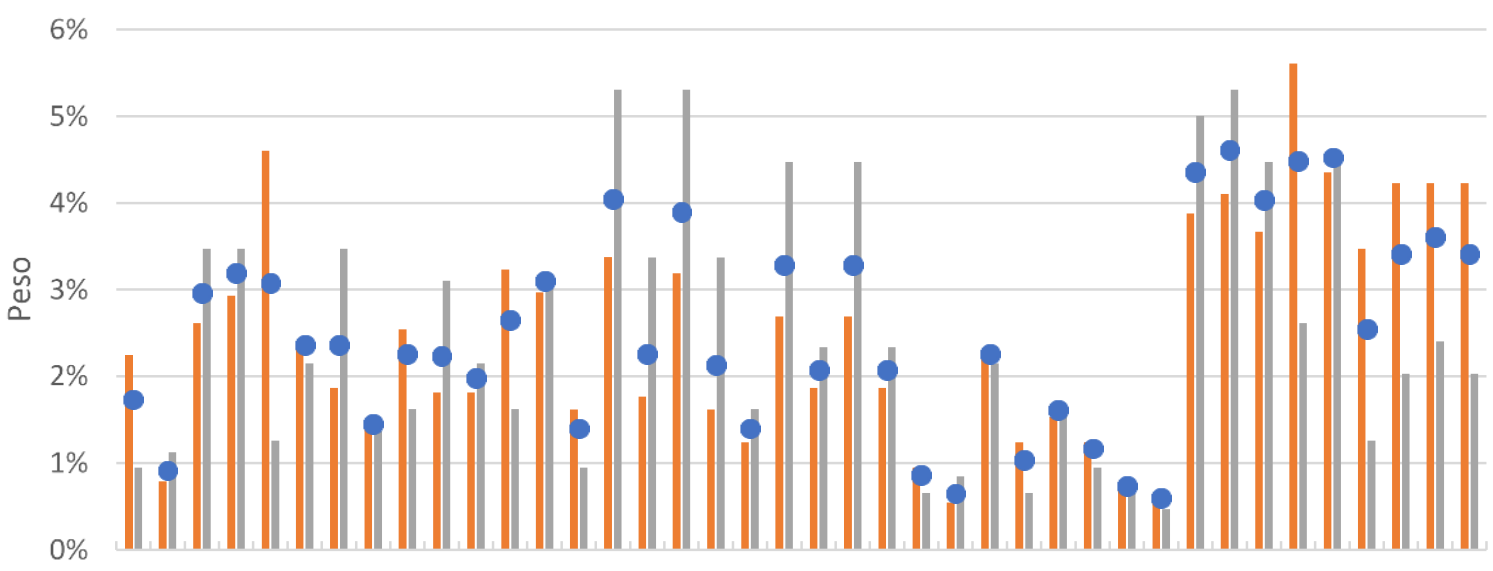

1234456778910111213141516171819202122232425262728293031323334353637383940 Item

- Média Projetistas Média Executores Média Geral

Fonte: Os autores.

FIGURA 5 - Hierarquização para o Sistema Predial de Esgoto Sanitário.

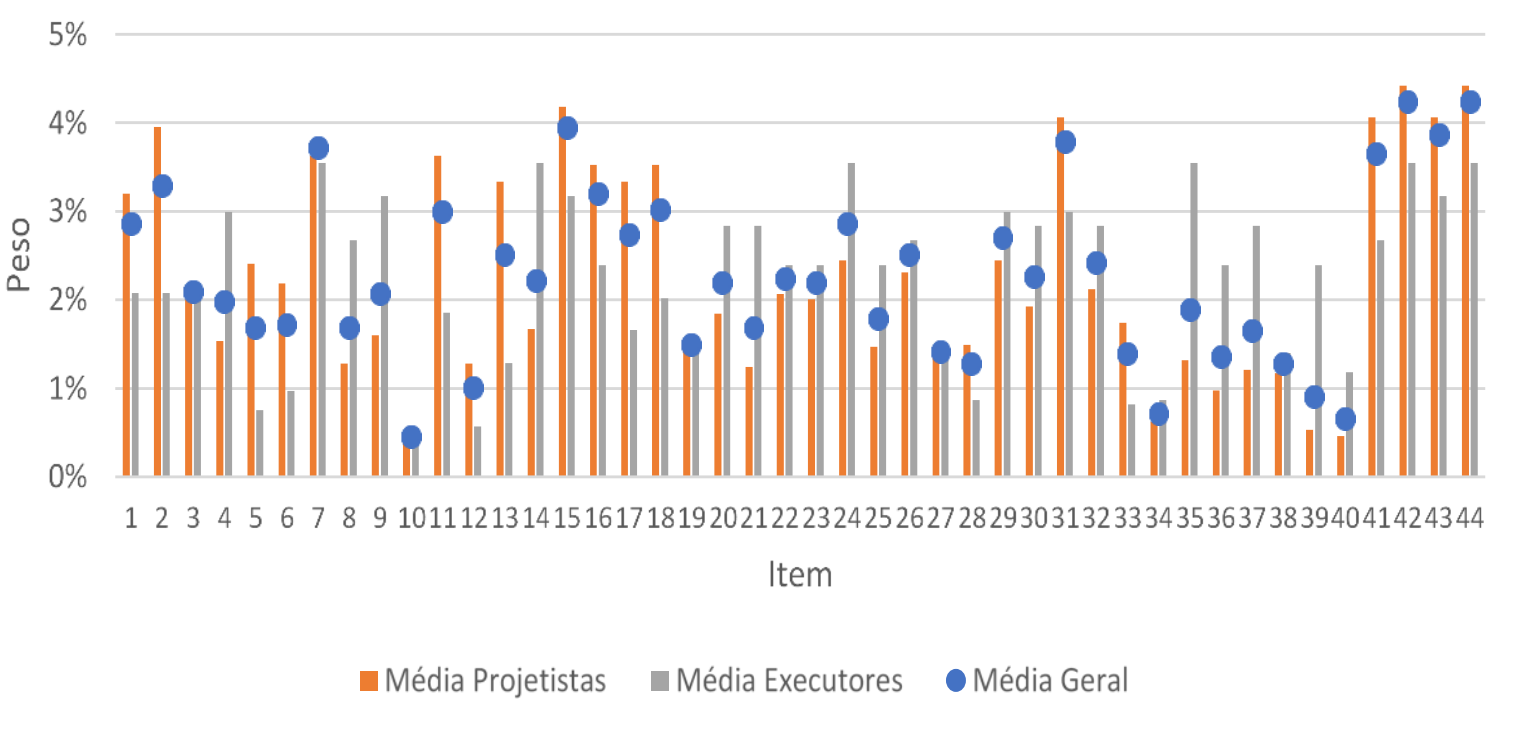

Fonte: Os autores. 
FIGURA 6 - Hierarquização para o Sistema Predial de Águas Pluviais.

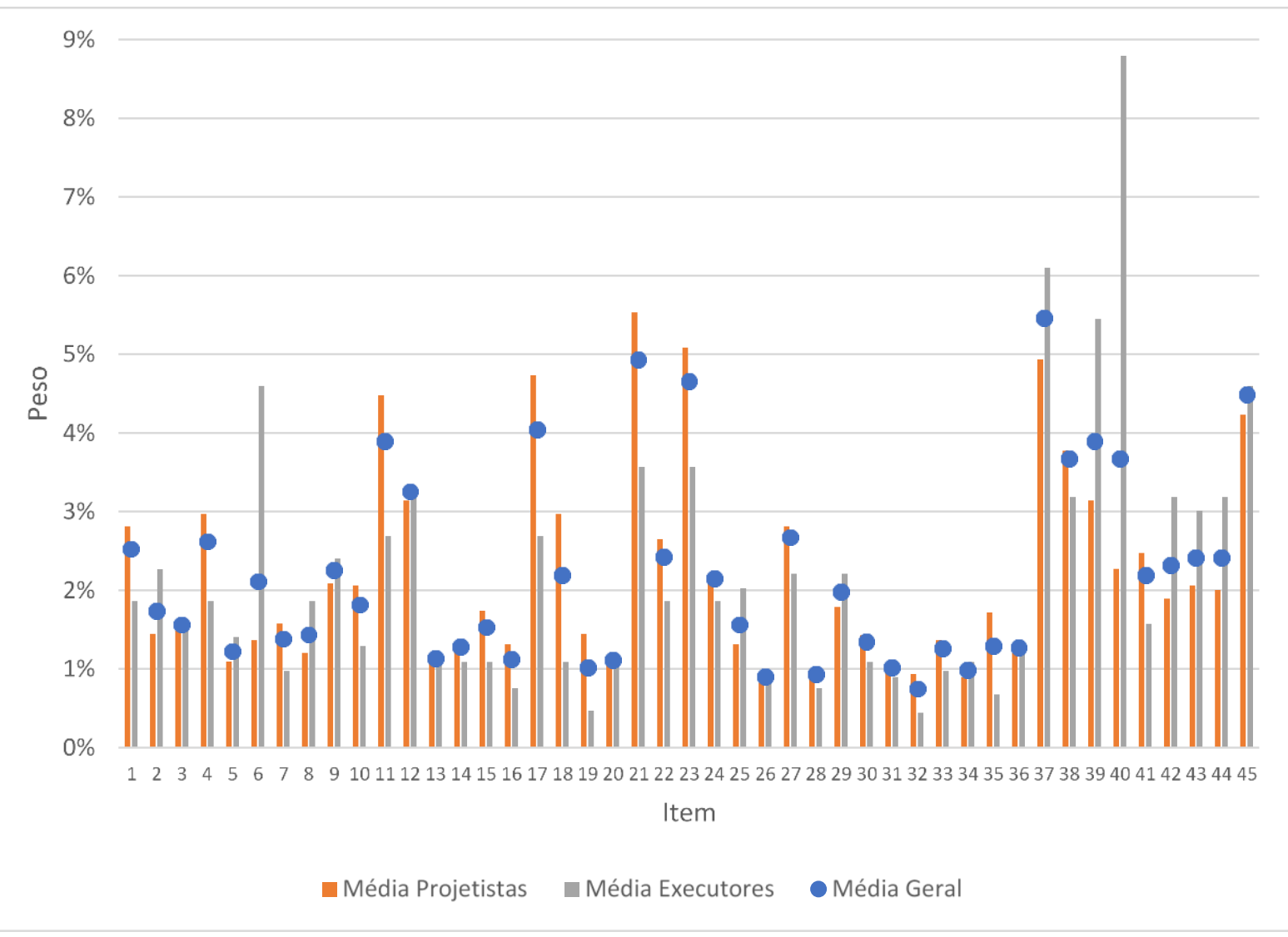

Fonte: Os autores.

\section{CONCLUSÕES}

Solucionado os dois problemas apresentados pela ferramenta proposta por Paixão, Silva e Reis (2016) obteve-se uma ferramenta aprimorada, capaz de identificar as principais não conformidades nos projetos hidráulicos e sanitários de edificações de diferentes finalidades. Ainda itens que envolvem projetos que buscam a sustentabilidade ambiental foram inseridos na ferramenta.

Ao se aperfeiçoar a ferramenta e através da aplicação do método de análise hierárquica (AHP) por diversos profissionais envolvidos tanto na elaboração de projetos quanto na execução de sistemas prediais hidráulicos e sanitários, foi possível hierarquizar as não conformidades levantadas que atingem os projetos hidráulicos e sanitários de acordo com seu grau de importância.

Deste modo, a ferramenta passou então a fornecer informações capazes de nortear a priorização das ações a serem tomadas para corrigir as não conformidades identificadas nos projetos ou prevenir que essas não conformidades se tornem patologias manifestas.

A aplicação do AHP a diferentes profissionais evidenciou a grande variação de opiniões entre os mesmos, não apenas entre as diferentes classes (projetistas e executores), mas também entre profissionais de uma mesma classe. Isso evidencia a subjetividade da interpretação de relevância dada a cada não conformidade, envolvendo muito as experiencias vividas por cada profissional. 
Quando não for possível ou viável a correção de todas as não conformidades identificadas, o profissional responsável pelas correções deve aplicar o AHP de modo a obter pesos para os itens identificados e assim determinar quais seriam os itens mais relevantes e assim determinar as ações prioritárias a serem tomadas. Pode-se ainda optar por não aplicar novamente o AHP e adotar os valores de pesos relativos apresentados nesta pesquisa, que reflete uma opinião média de diversos profissionais.

\section{REFERÊNCIAS}

CARVALHO JÚNIOR, R.; Patologias em Sistemas Prediais Hidráulicos-Sanitários. São Paulo: 1 ed. Editora Blucher, 2013. 216 p.

GNIPPER, S. F. Diretrizes para formulação de método hierarquizado para investigação de patologias em sistemas prediais hidráulicos e sanitários. 2010. 307p. Dissertação (Mestrado). Faculdade de Engenharia Civil, Arquitetura e Urbanismo, Universidade Estadual de Campinas, Campinas - SP, 2010.

GOMES, K. G. A. Um método multicritério para localização de unidades celulares de intendência da FAB. 2009. 150p. Dissertação (Mestrado). Programa de Pós-graduação em Engenharia de Produção da Pontifícia Universidade Católica do Rio de Janeiro, Rio de Janeiro - RJ, 2009.

PAIXÃO, T. C. R; SILVA, M. H. A; REIS, R. P. A. Proposição de ferramenta de avaliação qualitativa de projetos hidráulicos e sanitários prediais. XVI Encontro Nacional de Tecnologia do Ambiente Construído, ENTAC. São Paulo, São Paulo, 2016.

PASSOS, A. C. Definição de um índice de qualidade para distribuidoras de energia elétrica utilizando o apoio multicritério à decisão e análise de séries temporais. 2010. 101p. Dissertação (Mestrado). Programa de Pós-graduação em Engenharia Elétrica da Pontifícia Universidade Católica do Rio de Janeiro, Rio de Janeiro - RJ, 2010.

SAUTCHUCK Carla; et al. Conservação e reúso da água em edificações. FIESP - FEDERAÇÃO DAS INDÚSTRIAS DO ESTADO DE SÃO PAULO. São Paulo, 2005. 152 p.

SILVA, C. F. C.; SOUSA, R. V. R.; MONTEIRO, E. C. B. Análise das patologias de uma edificação da cidade do Recife - Estudo de caso. XII Encontro Nacional de Tecnologia do Ambiente Construído, ENTAC. Fortaleza, Ceará, 2008.

WOLFF, C. S. O método AHP - revisão conceitual e proposta de simplificação. 2008. 138p. Dissertação (Mestrado). Programa de Pós-graduação em Engenharia Industrial da Pontifícia Universidade Católica do Rio de Janeiro, Rio de Janeiro - RJ, 2008. 